\title{
A CASE SURVIVING SIX MONTHS AFTER TRAUMATIC RUPTURE OF THE AORTA
}

\author{
BY \\ ROLAND RODDA \\ From the Department of Pathology, Otago University Medical School, New Zealand
}

(RECEIVED FOR PUBLICATION JANUARY 9, 1953)

Rupture of the aorta has become familiar as a cause of rapid death, especially in certain accidents involving modern, fast transport (Helpern, 1952). Although the victims very seldom survive more than an hour (Strassmann, 1947) a case in which death was delayed for 20 days has been described by Rice and Wittstruck (1951). The following case records a ruptured aorta due to a football injury in which death occurred almost six months later.

\section{Clinical History}

A schoolboy, aged 10, was admitted to the Dunedin Hospital on January 27,1952 , with a two weeks' history of severe cough, vague upper abdominal pain, malaise, and pyrexia to the extent of $104^{\circ} \mathrm{F}$. He had sustained a fractured clavicle at football on August 20, 1951. On examination of the chest, diminished movement, harsh breath sounds, and crepitations were found on the left side and a provisional diagnosis of bronchopneumonia was made. On succeeding days a systolic basal cardiac murmur was heard which gradually became more pronounced. Blood pressure was $140 / 90 \mathrm{~mm}$. Hg. On February 13 his condition became worse, and more definite physical signs were elicited in the left chest. A radiograph showed an almost total collapse of the left lung, with a mediastinal shift and a small pleural effusion. During a bronchoscopy there was an alarming gush of blood in the left bronchus, but this rapidly subsided and he seemed improved. Next evening he complained of a sudden severe pain in the chest after which he rapidly became extremely shocked. He died a few hours later on February 15.

\section{Post-mortem Examination}

The body examined 13 hours after death showed no deformities and no evidence of recent injury. Gross and microscopical study of the alimentary, urogenital, haemopoietic, endocrine, and nervous systems showed only the capillo-venous congestion resulting from shock. There were soft, discrete, enlarged tracheo-bronchial lymph nodes.

Respiratory System.-The nasal passages, sinuses, larynx, and trachea were normal. The right pleural cavity was normal, but the left contained approximately $900 \mathrm{ml}$. of heavily blood-stained fluid and blood clot. Most of the upper posterior part of the left pleural cavity was occupied by a large mass projecting from the aortic arch and also pushing into the adherent postero-medial part of the left lung (Fig. 1). The right lung showed

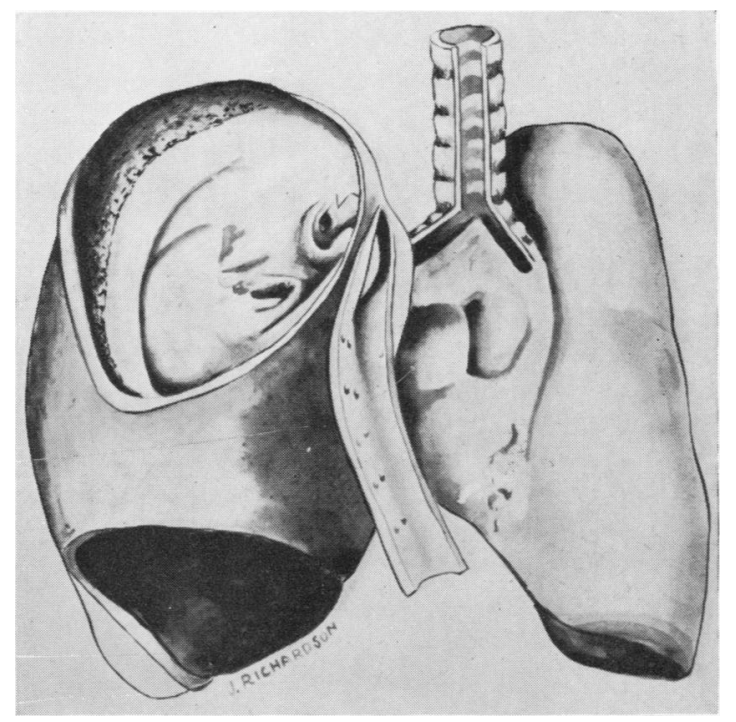

FIG. 1.-Drawing showing ruptured aortic arch and resultant false aneurysm cut open. Most of the aneurysm lining is smooth, but laterally blood clot overlies lung tissue where the aneurysm wall is deficient. The valvular opening into the left bronchus is shown below the aorta. The base of the left lung is partly cut away to show the haematoma in the lung substance.

hypostatic congestion and oedema. The left lung antero-lateral to the aortic mass was airless and almost filled with blood, and in both lobes posteriorly the lung tissues had been displaced by a massive subpleural blood clot. A rupture of the overlying basal pleura was the origin of the left haemothorax. The bronchi on the right were normal. In the stretched left main bronchus $3 \mathrm{~cm}$. from the carina and near the origin of the left 


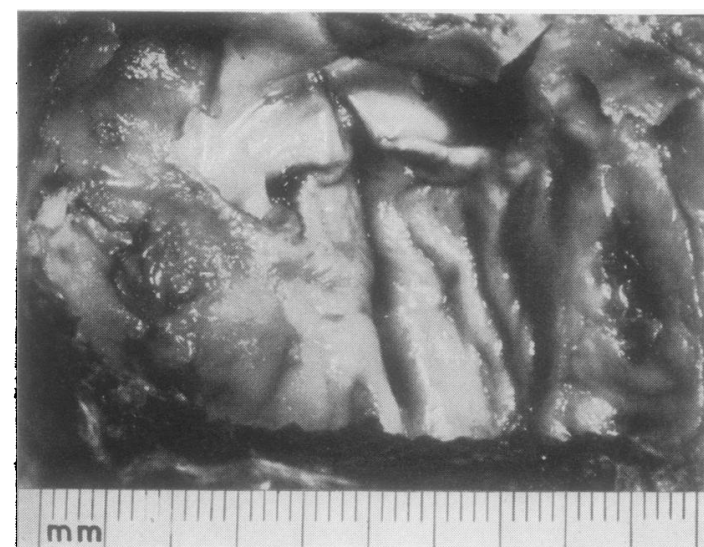

FIG. 2.-Photograph showing opening of aorta into the false aneurysm. The rounded edges of the flaps of torn aortic wall are splayed out on the wall of the aneurysm.

upper lobe bronchus there was a narrow erosion of the wall $0.3 \mathrm{~cm}$. in length, through which a probe could be passed into the aortic mass. The bronchial tree distal to this fistula was filled with blood.

Cardiovascular System.-The heart $(160$ g. $)$, its valves, and the pulmonary and systemic visceral arteries were normal. The ascending aorta was normal and measured $2.3 \mathrm{~cm}$. in circumference. The remainder of the aortic arch was split laterally for $2.5 \mathrm{~cm}$. of its length and opened into a smooth- lined, saccular, false aneurysmal cavity $10 \mathrm{~cm}$. in length and $6 \mathrm{~cm}$. in diameter, pushing into the lung and almost filling the upper posterior part of the left pleural cavity. The aneurysm wall was madeup of layered fibrous tissue several millimetres in thickness, but an extensive area of the lower part comprised thin fibrinous material only. Laterally, there was a ragged elliptical deficiencyes of the wall where the aneurysm merged with the blood-filled lung substance. The fistula from theaneurysm into the left bronchus appeared valvularw and closed by leaves of the layered fibrous wall.

The defect in the aortic wall (Fig. 2) was due to a stellate, whole-thickness tear, involving four-fifths of the aortic circumference. The flaps of tornaortic wall were splayed out on the aneurysm wall:cr The edges of the tear were rounded and quiteo smooth. The aortic intima showed no athero-sclerosis.

\section{Histology}

In the right lung there is marked oedema and $\vec{C}$ particularly at the base an acute congestion. In. the basal portions of the left lung the whole of the air passages are filled with blood and in somes areas a peribronchial acute inflammatory exudate is $\overline{ }$ present. At the left base posteriorly the lung tissues have been entirely replaced by the subpleural $\stackrel{\Phi}{\Phi}$ haematoma, and the overlying pleura shows an $\underset{\Rightarrow}{\Rightarrow}$ acute inflammatory exudate. In the left upper lobe $\frac{\rho}{3}$

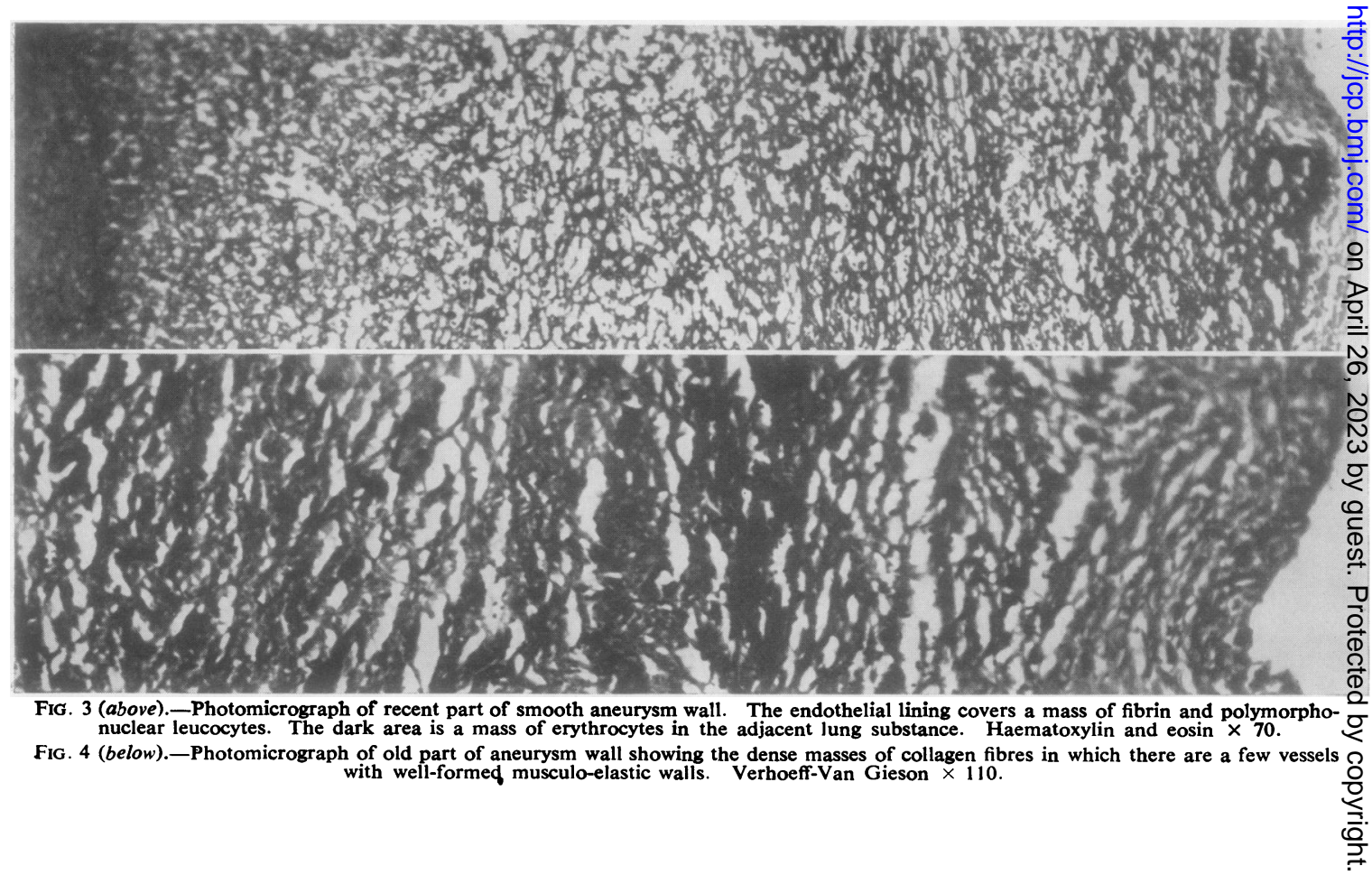


anteriorly and well away from the aneurysm there is a severe degree of collapse with alveolar foetalization, and many of the alveoli contain large mononuclear cells. In this area some vessels contain thrombi in which organization is beginning. Nearer the aneurysm the alveoli are filled and distended with blood in which there are very numerous large mononuclear cells. In a few of these phagocytes there are iron-containing pigment granules. Sections, which include the ragged aneurysm lining, show this to comprise fibrin, erythrocytes, leucocytes, cell debris, and torn portions of lung tissue. Amongst the latter are vessels, portions of vessels, and elastic tissue fragments. In this area the the wall indicate that the aneurysm has been present for months.

The edges of the aortic tear (Fig. 5) show a curling inwards of the muscle and elastic fibres and a partial covering by fibrous tissue. There is no evidence to indicate that elastic or muscular degeneration has preceded the rupture. Sections from the ascending aorta and the lower thoracic aorta show no medionecrosis.

\section{Discussion}

This case has none of the features of spontaneous rupture of the aorta, which seldom involves the whole thickness of the aortic wall but results in a

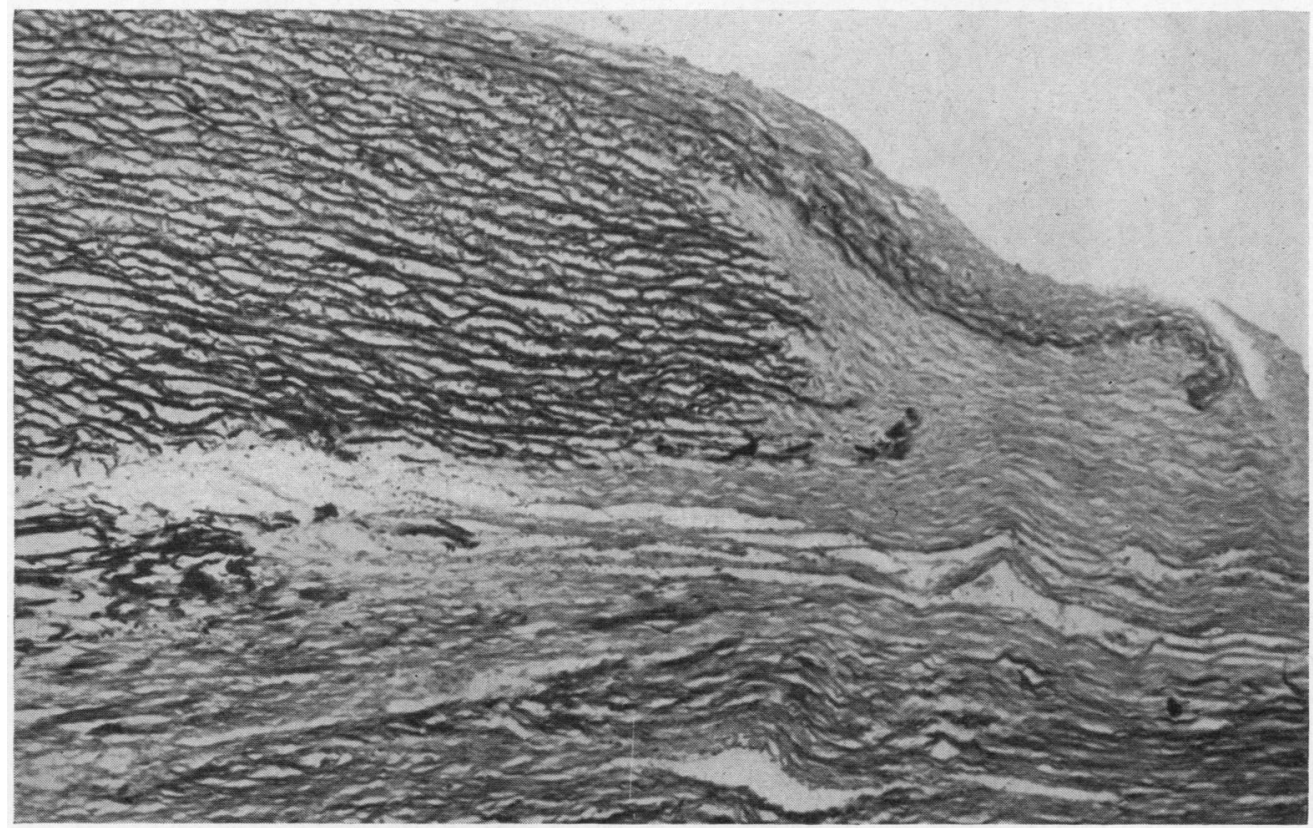

FIG. 5.-Photomicrograph showing the rounded edge of the torn aortic media lying on the collagenous tissue of the thick false aneurysm wall. Verhoeff-Van Gieson $\times 70$.

aneurysm wall has ruptured within the last few days.

Sections from the smooth fibrinous area in the lower part of the aneurysm wall (Fig. 3) show a lining of endothelium beneath which is a thick zone of inflammatory cells and fibrin. The appearances indicate that this part of the aneurysm wall has been in existence for rather more than a few days.

The older, intact part of the aneurysm wall (Fig. 4) is made up of layered, dense, collagenous fibrous tissue in which there is now little cellular activity. There is no capillary proliferation and the numerous vessels are well devaloped. The completeness of organization and the thickness of dissecting aneurysm which is rare in childhood (Shennan, 1934). In dissecting aneurysms, muscle and elastic degeneration is present in the media (Rottino, 1939) and sometimes the medionecrosis is characterized by mucoid cysts (Erdheim, 1930). The intimal tear which is the start of the dissection is also most often found in the ascending aorta (Sailer, 1942).

Klotz and Simpson (1932) have shown experimentally that in the absence of medial disease tremendous intra-aortic pressures are necessary to rupture the aorta, but Hass (1944) and Fidler (1949) describe cases with rupture of the healthy aorta due to severe indirect violence. The rupture 
is transverse and usually near the attachment of the obliterated ductus arteriosus. It is frequently the result of a fall from a height, a motor or an aircraft accident (Wilson, 1946). Although the mechanism of rupture has been disputed (Teare, 1951; Rutherford, 1951) a rapid deceleration of the body is an essential feature.

In this case the age and thickness of the fibrous tissue wall of the false aneurysm and the rounded nature of the edges of the aortic tear indicated that aortic rupture occurred some considerable time before death. Inquiry from the boy's guardian excluded any notable injury other than that when he fractured the clavicle six months before. Details of this event show that the injury was caused by a fall when he was tackled at football (he scored the try nevertheless). This accident must be regarded as providing the violent deceleration, resulting in aortic rupture and the formation of the false aneurysm. The gradual onset of respiratory symptoms a few weeks before death was due to the expansion of the aneurysm, and this was confirmed by the appearances of the immature tissue comprising the lower part of the wall. A small leakage of blood may have occurred at this stage, but the exacerbation of symptoms two days before death was the result of extensive rupture of the aneurysm and formation of the large intrapulmonary haematoma. The subsidence of the bronchial haemorrhage at bronchoscopy can be explained only by the valvular fistula closing after withdrawal of the instrument from the left bronchus. Death was: due to a massive haemothorax from a rupture of the pleura overlying the lung haematoma.

\section{Summary}

A case is described of a 10-year-old boy whon sustained an injury at football which resulted in aortic rupture with the formation of a false $\vec{\circ}$ aneurysm. Rupture of the false aneurysm led to a massive pulmonary haematoma and a fatal haemo- $\omega$ thorax six months after the injury.

I am indebted to Dr. M. McGeorge for the clinicalo details of this case. My thanks are also due to Dr. J. E. McCoy, who made the post-mortem examination, to $\vec{G}$ Mrs.J. Richardson for the drawing, to Mr. B. McPhersono for preparing the sections, and to Miss D. Marshall and Mr. G. Brooks for the photographs.

\section{REFERENCES}

Erdheim, J. (1930). Virchows Arch. path. Anat., 276, 187.

Frdheim, J. (1930), Virchows Arch. path. Anat., 276

Hass, G. M. (1944). J. Aviat. Med., 15, 77.

Helpern, M. (1952). Quoted by DuBois, E. F., Brit. med. J., 2, 685.

Klotz, O., and Simpson, W. (1932). Amer. J. med. Sci., 184, 455.

Rice, W. G., and Wittstruck, K. P. (1951). J. Amer. med. Ass., 147, 915.

Rottino, A. (1939). Arch. Path., Chicago, 28, 1

Rutherford, P. S. (1951). Brit. med. J., 2, 1337.

Sailer, S. (1942). Arch. Path., Chicago, 33, 704.

Shennan, T. (1934). Spec. Rep. Ser. med. Res. Coun., Lond., No. 193 .

Strassmann, G. (1947). Amer. Heart J., 33, 508.

Teare, D. (1951). Brit. med. J., 2, 707.
Wilson, J. V. (1946). The Pathology of Traumatic Injury, pp. 111-112. Livingstone, Edinburgh. 